\title{
Patients' Satisfaction on Services of Border Guard Hospital, Guimara, Bangladesh
}

\author{
Wahab MA ${ }^{1}$, Zafreen $\mathrm{F}^{2}$, Ahmad $\mathrm{MU}^{3}$, Rahman $\mathrm{MH}^{4}$, Razzak $\mathrm{MA}^{5}$
}

DOI: https://doi.org/10.3329/jafmc.v15i1.48632

\begin{abstract}
Introduction: Patients' satisfaction is one of the established yard sticks to measure success of the hospitals. To improve the quality of services, health organizations use patient satisfaction survey to evaluate their processes delivered. A satisfied patient is more likely to develop a deeper and longer lasting relationship with their medical service providers, leading to improved compliance, continuity of care, and ultimately better outcomes.

Objectives: To assess the patients satisfaction with services provided and the infrastructure facilities of Border Guard Hospital, Guimara (BGHG), of Khagrachari district Bangladesh.

Materials and Methods: This descriptive cross sectional study was conducted among the patients who attended the outpatient department of BGHG from January to December 2017. Total 1340 patients aged more than 18 years, irrespective of sex, having no serious complications and willing to participate were selected by convenient sampling. Data were collected by semi-structured questionnaire by face to face interview and analyzed by SPSS 21.0.
\end{abstract}

Results: Out of 1340 respondents $53.7 \%$ were serving $B G B$ members, $18.3 \%$ were BGB families and $28.0 \%$ respondents were local residents. Majority of the patients stated that the general basic facilities at the hospital were adequate. Regarding cleanliness $94.7 \%$, waiting room sitting facilities $91.9 \%$, drinking water availability $88.4 \%$, lighting arrangement $96.7 \%$, ventilation arrangement $88.1 \%$ and toilet facilities $91.1 \%$ respondents reported that the hospital facilities were adequate. Most of the respondents were satisfied with the quality of professional services by all type of staffs of the hospital. Highest $84.9 \%$ of the respondents were satisfied with doctors' attitude, behavior and cooperation. About other staffs; $72.9 \%$ respondents were satisfied with attitude, behavior and cooperation of nurses, $71.9 \%$ with pharmacists, $71.1 \%$ with registration clerk, $75.3 \%$, with information desk, $70.2 \%$ with guards and $73.8 \%$ with supporting staffs.

Conclusion: Patients attended at BGHG was highly satisfied about the infrastructure and the services provided the hospital. But few percentages of patients expressed their dissatisfaction. BGHG authority should keep it up and try to improve further.

Key-words: Patient satisfaction; Outpatient department, Border Guard hospital.

\section{Introduction}

Human satisfaction is a complex concept that is related to a number of factors including lifestyle, past experiences, future expectations and the value of both individual and society ${ }^{1}$. Patients' satisfaction is a component of health care quality and is increasingly being used to assess medical care in many countries in the world. Until recently, traditional assessments of medical care were done purely in terms of technical and psychological reports of outcomes. It is an established fact that satisfaction influences whether a person seeks medical advice, complies with treatment and maintains a continuing relationship with practitioners ${ }^{2}$. Concept of satisfaction is fast changing all over the world ${ }^{3}$. Patient satisfaction is one of the established yard sticks to measure success of the services being provided in the hospitals ${ }^{4}$. Improved socioeconomic status and easier access to medical care has led to high expectations and demands from consumers of hospital services ${ }^{4}$. For health care organization to be successful monitoring of customer's perception is a simple but important strategy to assess and improve their performance ${ }^{5,6}$. A patient is the ultimate consumer of the hospital. He is the person in distress. He expects from hospital comfort, care and cure ${ }^{7}$. Patient forms certain expectations prior to visit. Once the patients come to the hospital and experience the facilities, they may become either satisfied or dissatisfied ${ }^{8}$.

Patient satisfaction has long being considered an important component when measuring health outcomes and quality of care. The rising strength of consumerism in society highlights the central role of patient's attitude play in health planning and delivery?. Furthermore, a satisfied patient is more likely to develop a deeper and longer lasting relationship with their medical providers, leading to improved compliance, continuity of care, and ultimately better outcomes ${ }^{10}$. Keeping this background in mind the present study was undertaken to assess the quality of care provided in outpatient department of Border Guard Hospital, Guimara (BGHG) of Khagrachari district Bangladesh, regarding patients' satisfaction.

\section{Materials and Methods}

This descriptive cross sectional study was conducted among the patients who attended the outpatient department of BGHG from January to December 2017. Total 1340 patients aged more than 18 years, irrespective of sex, and willing to participate were selected. Patients who were who regretted, who were working in the hospital and patients with severe physical or mental illness were excluded from the study. Informed verbal consent was taken from each patient and they were ensured about the confidentiality. A semi-structured pretested questionnaire was used which included socio-demographic profile and certain domains of satisfaction such as basic facilities, satisfaction towards OPD services regarding courtesy and quality of care. Face to face interview was taken to collect data. The patients were requested to give rating to the 3 points rating scale as following; 1) satisfied, 2) neither satisfied nor dissatisfied and 3) dissatisfied.

1. Lt Col Md Abdul Wahab, MBBS, MD, Associate Professor of Biochemistry, AFMC, Dhaka (E-mail: wahab947@gmail.com) 2. Dr Farzana Zafreen, MBBS, MPH, Associate Professor \& Head, Department of Community Medicine, Medical College for Women and Hospital, Uttara, Dhaka. 3. Brig Gen Mohsen Uddin Ahmed, MBBS, MHI, MPH, Deputy Commandant \& Director Training, AFMC, Dhaka 4. Brig Gen Md Habibur Rahman, MBBS, FCPS, Professor \& Head, Department of Medicine, AFMC, Dhaka 5. Brig Gen Md. Abdur Razzak, MBBS, MCPS, FCPS, APLAR Fellow in Rheumatology, Chief Physician, CMH, Dhaka. 
Collected data were analyzed by SPSS 21.0 and qualitative data were expressed as frequency and percentage.

\section{Results}

Out of 1340 respondents $720(53.7 \%$ ) were serving BGB members, $245(18.3 \%)$ were BGB families and $375(28.0 \%)$ respondents were local residents. Majority 436(32.5\%) respondents was within 41-50 years of age followed by $355(26.5 \%)$ within $31-40$ years and $287(12.4 \%$ ) within $51-60$ years of age. Male respondents were $915(68.3 \%)$ and $425(31.7 \%)$ were female. Respondents' education status found $521(38.0 \%)$ were SSC level followed by HSC 364(27.2\%) and primary 265(19.8\%). Among the respondents $763(56.9 \%)$ were service holder and $264(19.7 \%)$ were housewife. Regarding monthly family income $788(58.8 \%)$ respondents had Taka $20000-30000$ followed by $336(25.1 \%)$ had 10000-20000 Taka (Table-I).

Majority of the patients stated that the general basic facilities at the hospital were adequate. Regarding cleanliness $1269(94.7 \%)$, waiting room sitting facilities 1231(91.9\%), drinking water availability $1185(88.4 \%)$, lighting arrangement 1296(96.7\%), ventilation arrangement 1180(88.1\%) and toilet facilities $1221(91.1 \%)$ respondents reported that the hospital facilities were adequate (Table-II). Most of the respondents were satisfied with the quality of professional services by all type of staffs of the hospital. Highest $1137(84.9 \%)$ of the respondents were satisfied with doctors attitude, behavior and cooperation. About other staffs; 977(72.9\%) respondents were satisfied with attitude, behavior and cooperation of nurses, 963(71.9\%) with pharmacists, 952(71.1\%) with registration clerk, 1009(75.3\%) with information desk, $941(70.2 \%)$ with guards and $989(73.8 \%)$ with supporting staffs (Table-III).

Table-I: Socio-demographic characteristics of the respondents $(n=1340)$

\begin{tabular}{|c|c|c|c|}
\hline \multicolumn{2}{|c|}{ Characteristics } & Frequency & Percentage \\
\hline \multirow{3}{*}{ Type of patients } & BGB members & 720 & 53.7 \\
\hline & BGB families & 245 & 18.3 \\
\hline & Locals & 375 & 28.0 \\
\hline \multirow{6}{*}{ Age in years } & $\leq 20$ & 95 & 7.1 \\
\hline & $21-30$ & 104 & 7.8 \\
\hline & $31-40$ & 355 & 26.5 \\
\hline & $41-50$ & 436 & 32.5 \\
\hline & $51-60$ & 287 & 21.4 \\
\hline & $>60$ & 63 & 4.7 \\
\hline \multirow{2}{*}{ Sex } & Male & 915 & 68.3 \\
\hline & Female & 425 & 31.7 \\
\hline \multirow{5}{*}{ Education status } & Illiterate & 103 & 7.7 \\
\hline & Primary & 265 & 19.8 \\
\hline & SSC & 521 & 38.9 \\
\hline & $\mathrm{HSC}$ & 364 & 27.2 \\
\hline & Graduate \& above & 87 & 6.4 \\
\hline \multirow{5}{*}{ Occupation } & Service holder & 763 & 56.9 \\
\hline & Housewife & 264 & 19.7 \\
\hline & Cultivator & 95 & 7.1 \\
\hline & Students & 122 & 9.1 \\
\hline & Others & 96 & 7.1 \\
\hline \multirow{4}{*}{ Family income (Taka) } & $<10,000$ & 151 & 11.3 \\
\hline & $10,000-20,000$ & 336 & 25.1 \\
\hline & $20,000-30,000$ & 788 & 58.8 \\
\hline & $>30,000$ & 65 & 4.8 \\
\hline
\end{tabular}

Table-II: General basic facilities in the hospital $(n=1340)$

\begin{tabular}{|l|c|c|}
\hline \multicolumn{1}{|c|}{ Basic Facilities } & Adequate & Inadequate \\
\hline Cleanliness & $1269(94.7)$ & $71(5.3)$ \\
\hline Waiting room sitting facilities & $1231(91.9)$ & $109(8.1)$ \\
\hline Drinking water & $1185(88.4)$ & $155(11.6)$ \\
\hline Lighting arrangement & $1296(96.7)$ & $44(3.3)$ \\
\hline Ventilation & $1180(88.1)$ & $160(11.9)$ \\
\hline Toilets & $1221(91.1)$ & $119(8.9)$ \\
\hline Signboards locating departments & $1204(89.9)$ & $136(10.11)$ \\
\hline
\end{tabular}

Table-III: Satisfaction of the respondent's towards OPD services $(n=1340)$

\begin{tabular}{|l|c|c|c|}
\hline \multicolumn{1}{|c|}{ Behaviour of } & Satisfied & Neither satisfied nor dissatisfied & Dissatisfied \\
\hline Doctors & $1137(84.9)$ & $140(10.4)$ & $63(4.7)$ \\
\hline Nurses & $977(72.9)$ & $238(17.8)$ & $123(9.3)$ \\
\hline Pharmacist & $963(71.9)$ & $211(15.7)$ & $166(12.4)$ \\
\hline Registration clerk & $952(71.1)$ & $247(18.4)$ & $141(10.5)$ \\
\hline Information desk & $1009(75.3)$ & $213(15.9)$ & $118(8.8)$ \\
\hline Guards & $941(70.2)$ & $176(13.1)$ & $223(16.7)$ \\
\hline Support staff & $989(73.8)$ & $197(14.7)$ & $154(11.5)$ \\
\hline
\end{tabular}

\section{Discussion}

In this study $53.7 \%$ respondents were serving BGB members, $18.3 \%$ were $B G B$ families and $28.0 \%$ respondents were local residents. Since the location of $B G H G$ is in a remote area of Khagrachari district, where health care facilities are not easily available thus BGHG used to serve the local people also. Majority of the patients stated that the general basic facilities at the hospital were adequate; regarding cleanliness $94.7 \%$, waiting room sitting facilities $91.9 \%$, drinking water availability $88.4 \%$, lighting arrangement $96.7 \%$, ventilation arrangement $88.1 \%$ and toilet facilities $91.1 \%$ respondents reported that the hospital facilities were adequate. These findings are consistent with other similar studies ${ }^{11,12}$. Another study done in Islamabad, Pakistan observed that $90.5 \%$ patients were satisfied with cleanliness of hospital ${ }^{13}$ and study done in Madhya Pradesh India ${ }^{14}$ also found $65 \%$ patients satisfied with cleanliness.

Most of the respondents were satisfied with the quality of professional services by all type of staffs of the hospital. Highest $84.9 \%$ of the respondents were satisfied with doctors' attitude, behavior and cooperation. This finding is higher than the other studies in military hospital in Bangladesh ${ }^{15}$. About $72.9 \%$ respondents were satisfied with attitude, behavior and cooperation of nurses. This finding is consistent ${ }^{4,11}$ with other similar studies but inconsistent ${ }^{9,13}$ with others. About $71.9 \%$ respondents were satisfied with pharmacists. This findings is almost similar with the study done in Saudi Arabia ${ }^{16}$. About $71.1 \%$ patients were satisfied with attitude, behavior and cooperation registration clerk, $75.3 \%$ with information desk, $70.2 \%$ with guards and $73.8 \%$ with supporting staffs. These findings are consistent with similar studies ${ }^{3,17}$, but state was better than other studies ${ }^{4,15}$. The present study observed that majority of the patients expressed satisfaction towards OPD services regarding courtesy and quality 
of care. The patients were more satisfied with the behaviour of doctors as compared to the behaviour of nurses, pharmacists and other staff.

\section{Conclusion}

Patient's satisfaction is a useful measure to provide an indicator of quality in health care services. It is a powerful management tool to capture the voice of the consumer. It is also an important tool to determine the success of health care facility. OPD is the first point of contact with the patients and serves as the shop window to any health care services. The care in the OPD indicates the quality of services of any hospital and it is reflected by patient's satisfaction with the services being provided. Patients attended at BGHG were highly satisfied about the infrastructure and the services provided the hospital. But few percentages of patients expressed their dissatisfaction. BGHG authority should keep it up and try to improve further.

\section{References}

1. Andaleeb SS, Siddiqui $N$ and Khandakar S. Patient satisfaction with health services in Bangladesh. Health policy and planning (Oxford Journals) 2007; 22(4):263-73.

2. Bhattacharya $A$, Menon $P$, Koushal $V$, et al. Study of Patient Satisfaction in a Tertiary Referral Hospital. Journal of Academy of Hospital Administration 2003; 15(1):1-6.

3. Bowling $A$, Rowe $G$ and McKee M. Patients' experiences of their healthcare in relation to their expectations and satisfaction: A population survey. Journal of the Royal Society of Medicine 2013; 106:143-9.

4. Atahar M and Chakravarty A. Patient satisfaction with services of outpatient department. Medical Journal Armed Forces India 2014; 70:237-42.

5. Joshi K, Sochaliya K, Purani S et al. Patient satisfaction with health care services: A cross sectional study of patients who visit the outpatient department of a civil hospital at Surendranagar, Gujrat IJMSPH 2013; 2(3):659-63.

6. Galhotra A, Sarpal SS, Gupta S et al. A Cross-Sectional Study on Patient Satisfaction Toward Services Received at Rural Health
Centre, Chandigarh, North India. Ann Trop Med Public Health 2013; 6(2):240-4.

7. Adamu $\mathrm{H}$ and Oche MO. Patient Satisfaction with Services at a General Outpatient Clinic of a Tertiary Hospital in Nigeria. British Journal of Medicine \& Medical Research 2014; 4(11):2181-202.

8. Soleimanpour H, Gholipouri C, Salarilak S, et al. Emergency department patient satisfaction survey in Imam Reza Hospital, Tabriz, Iran. International Journal of Emergency Medicine 2011; 4(2):1-7.

9. Margolis SA, Al-Marzouq S, Revel T et al. Patient Satisfaction with Primary Health Care Services in the United Arab Emirates. Journal in Health Care 2003; 15(3):241-9.

10. Ganasegeran K, Perianayagam W, Manaf RA et al. Patient Satisfaction in Malaysia's Busiest Outpatient Medical Care. The Scientific World Journal 2015: 1-6.

11. Islam MZ and Jabbar MA. Patients' Satisfaction of Health Care Services Provided at Out Patient Department Of Dhaka Medical College Hospital. Ibrahim Medical College Journal 2008; 2(2):55-7.

12. Hizlinda T, Teoh SY, Siti Nurbaiyah KE et al. A Cross-Sectional Study on Patient Satisfaction with Universiti Kebangsaan Malaysia Medical Centre (UKMMC) Primary Care Clinic. Med and Health 2012; $7(1): 12-23$.

13. Shaikh BT, Mobeen N, Azam SI et al. Using SERVQUAL for assessing and improving patient satisfaction at a rural health facility in Pakistan. Eastern Mediterianean Health Journal 2008; 14(2):447-56.

14. Pawar AA and Mukherji S. A Survey Cum Study On the level of satisfaction with the quality and delivery of healthcare at INHS Sanjivani. J Mar Med Soc 2011; (13):119-23.

15. Mohamed EY, Sami W, Alotaibi A et al. Patients' Satisfaction with Primary Health Care Centers' Services, Majmaah, Kingdom of Saudi Arabia. Int J Health Sci (Qassim) 2015; 9(2):163-70.

16. Raheem AR, Nawaz A, Fouzia N et al. Patients' Satisfaction and Quality Health Services: An Investigation from Private Hospitals of Karachi. Research Journal of Recent science 2014; 3(7):34-8.

17. Jawahar SK. A Study on Out Patient Satisfaction at a Super Specialty Hospital in India. Internet Journal of Medical Update 2007; 2(2):13-7. 